\title{
基于林冠塔吊的附生植物生态学研究进展
}

\author{
吴 毅 ${ }^{1,2}$ 刘文耀 ${ }^{1}$ 宋 亮 ${ }^{*}$ 陈 䂀 1,2 卢华正 ${ }^{1,2}$ 李 苏 ${ }^{1}$ 石贤萌 ${ }^{1,2}$
}

${ }^{1}$ 中国科学院西双版纳热带植物园热带森林生态学重点实验室, 云南预腊 $666303{ }^{2}{ }^{2}$ 中国科学院大学, 北京 100049

摘 要 林冠是生物圈中物种最丰富却最鲜为人知的生境之一。它在森林与大气的物质、能量交换过程中发挥着至关重要的 作用。但因林冠调查技术的限制, 林冠及生存在其中的附生植物在生态系统中的功能尚未得到足够的重视。塔吊在三维空间 中作业具有 “全方位、高精度、非破坏、可重复”的特征。林冠塔吊已成为当前林冠学研究的标志, 并为林冠附生植物研究提 供了契机。国际上，欧美国家利用塔吊技术对林冠层附生植物多样性与空间分布等进行了大量的研究，取得了丰硕的成果。 该文介绍了塔吊的构造、林冠塔吊建设历史和站点分布及国际林冠研究组织等概况, 并对依托塔吊开展的附生植物研究进展 进行了评述。此外, 还简要介绍了我国塔吊建设与林冠生态学发展情况。在系统分析国内外附生植物研究现状基础上, 从附 生植物多样性、附生植物空间格局与维持机制、生态适应性、与林冠动物的关系以及附生植物对气候变化的响应等5个方面 对今后基于林冠塔吊开展附生植物研究进行了展望。

关键词＼cjkstart林冠塔吊; 附生植物; 生物多样性; 空间分布格局; 生态适应; 气候变化

引用格式: 吴毅, 刘文耀, 宋亮, 陈㬢, 卢华正, 李苏, 石贤萌 (2016). 基于林冠塔吊的附生植物生态学研究进展. 植物生态学报, 40, 508-522. doi: 10.17521/cjpe.2015.0424

\section{Advances in ecological studies of epiphytes using canopy cranes} \author{
WU Yi ${ }^{1,2}$, LIU Wen-Yao ${ }^{1}$, SONG Liang ${ }^{1 *}$, CHEN Xi ${ }^{1,2}$, LU Hua-Zheng ${ }^{1,2}$, LI Su ${ }^{1}$, and SHI Xian-Meng ${ }^{1,2}$ \\ ${ }^{1}$ Key Laboratory of Tropical Forest Ecology, Xishuangbanna Tropical Botanical Garden, Chinese Academy of Sciences, Mengla, Yunnan 666303, China; and \\ ${ }^{2}$ University of Chinese Academy of Sciences, Beijing 100049, China
}

\section{Abstract}

Forest canopies are one of the most species-rich habitats, but among the least explored in the biosphere. They play a crucial role in the process of material and energy exchange between the forest and atmosphere. Individual ecosystem members (e.g., epiphytes) and the ecological function of canopies have been given insufficient attention because of inaccessibility. Canopy cranes have been successfully used to guarantee non-destructive and reiterated sampling of epiphytes, thus offering a top-down perspective of the entire canopy. These cranes have become the symbol of canopy research and enable epiphyte research. Globally, western developed countries have conducted many studies of diversity and spatial distributions of epiphytes using canopy cranes, thus accumulating an abundance of valuable results. This review summarizes the structure, development history, and distribution of canopy cranes as well as general information about international canopy research organizations. Ecological studies of epiphytes performed around the world using these canopy cranes are also reviewed. Additionally, the development of canopy ecology and the construction of canopy cranes in China are introduced briefly. In analyzing current research trends in ecological studies of epiphytes in China and globally, the following aspects were considered: biodiversity, spatial patterns and maintenance mechanisms, ecological adaptations of epiphytes, their relationship with canopy animals, and their responses to climate change.

Key words canopy crane; epiphytes; biodiversity; spatial distribution pattern; ecological adaptation; climate change

Citation: Wu Y, Liu WY, Song L, Chen X, Lu HZ, Li S, Shi XM (2016). Advances in ecological studies of epiphytes using canopy cranes. Chinese Journal of Plant Ecology, 40, 508-522. doi: 10.17521/cjpe.2015.0424

作为森林地表以上全部树冠的集合，林冠 (forest canopy)包括所有的叶片、枝条、小枝及附生
植物 (Nadkarni et al., 1996; Lowman \& Rinker, 2004)。三维空间的异质性及垂直分层使林冠蕴含了

收稿日期Received: 2015-11-23 接受日期Accepted: 2016-02-19

* 通信作者Author for correspondence (E-mail: songliang@xtbg.ac.cn) 
全球 $40 \%$ 的陆地生物多样性，其中 $10 \%$ 是林冠专有 类群(Hopkin, 2005)。长期以来, 因缺乏有效的技术 手段调查林冠层, 大部分林冠研究局限于森林地面 0-2 m范围内(Lowman \& Schowalter, 2012)。毫无疑 问, 这个有限的研究高度会导致不全面的结论。林 冠被视为 “最后的生物前沿” (the last biological frontier)、“地球的第八大洲”, 是生物圈中物种丰富却最 鲜为人知的生境之一(Stork, 2007b)。人类对深海和 外太空的探索均早于对林冠的研究, 林冠生物多样 性格局和生态过程仍被视为“科学黑箱” (Parker et al., 1992; Lowman et al., 2012)。

林冠调查技术的革新为科学家探索该未知领域 提供了有效工具。望远镜、梯子、单绳攀爬技术、 空中走廊、热气球和林冠筏、塔吊等技术先后被用 于林冠研究(Lowman, 2001; 杨洁等, 2008)。其中, 林冠塔吊(canopy crane)的起重臂(jib)可旋转 $360^{\circ}$, 携带的吊篮(gondola)可水平延伸和垂直起降, 能安 全地把研究人员和仪器投放至林冠三维空间的指定 位置, 开展林冠层的生物多样性与生态过程及其对 环境变化响应等方面的研究工作 (Hopkin, 2005; Pennisi, 2005)。塔吊在林冠研究中的作用如同水肺 系统(scuba system)(Stork, 2007b; Lowman et al., 2012)或深海潜水器(deep-sea submersible) (Mitchell et al., 2002)在开展海洋生物学研究中一样不可或 缺。当人们具备进入冠层的能力后, 才逐渐认识到 林冠是全球陆地生物群系与大气层的功能界面 (functional interface), 在提供局域和全球生态系统 服务以及森林与大气的物质、能量交换过程中发挥 着至关重要的作用(Ozanne et al., 2003)。

附生植物 (epiphyte) 是依赖乔木宿主提供结构 性支撑的非寄生植物(Laube \& Zotz, 2006b; Zotz, 2013)。植物进化为附生生活型后能获得更多的光 照、逃避捕食者并提高传粉效率, 但因根系失去了 与土壤接触的机会而面临较为严重的水分和养分胁 迫。它们暴露在空气中, 直接吸收空气中的水分和 养分以维持其生命过程, 对环境变化具有高度敏感 性(Benzing, 2012)。同时, 作为热带山地森林物种最 为丰富的类群之一, 附生植物具有重要的生态功能, 它们在维系森林生态系统的物种多样性(Kromer et al., 2013), 截留大气水分、促进养分循环(Zotz \& Winkler, 2013), 为其他生物提供林冠栖息地和食物 (Nadkarni et al., 2011)等方面发挥着重要作用。但与
陆生植物相比, 附生植物是研究得最少的植物类群, 它们的多样性、空间结构与动态等方面研究得还很 不充分(Bartels \& Chen, 2012; Mendieta-Leiva \& Zotz, 2015)。

林冠代表优先保护的生态系统和科学研究前沿, 推动着科普教育的发展(Lowman et al., 2012)。当前, 世界上超过一半以上的森林遭到砍伐、火烧或商业 收获。Mitchell (2001)预测, 在21世纪末将只剩下原 来5\%-10\%的雨林林冠层尚处于原始状态, 林冠生 境正面临重大危机(Batke, 2012)。林冠及其组分位于 森林与大气层相互作用的关键交互界面, 对环境变 化极为敏感, 具有生物指示作用。这使之成为监测 气候变化的“矿井中的金丝雀”(canary in the coal mine), 能为全球变化研究提供早期识别技术和预 警措施(Lowman et al., 2013)。林冠是蕴含丰富物种 但又受严重威胁的复杂生境, 受到生态学、气候学、 环境科学的关注, 成为保护生物学和全球变化生态 学的热点(Ozanne et al., 2003)。

世界上首座林冠塔吊建立至今已有25年(Parker et al., 1992), 而基于林冠塔吊的首次附生植物研究 已有15年(Nieder et al., 2000)。尽管依托塔吊的附生 植物研究分别在种群动态(Laube \& Zotz, 2006a)、物 种多样性与空间格局(Zotz \& Schultz, 2008)、叶片功 能性状(Petter et al., 2015)等方面取得了令人关注的 研究成果, 但基于林冠塔吊的附生植物研究综合评 述却未见报道。在建设“中国生物多样性监测与研究 网络” (Sino BON)的背景下, 有必要对全球依托林 冠塔吊开展的附生植物研究历程、现状和趋势进行 分析和归纳, 以期为我国的Sino BON建设提供参考 (马克平, 2015)。本文的主要目标是: (1)简要介绍塔 吊的结构与特征、林冠塔吊建设历史和各个塔吊站 点及国际林冠组织概况; (2)围绕在塔吊上开展的附 生植物研究进行综述; (3)结合当前附生植物领域的 研究重点, 对我国基于林冠塔吊开展附生植物研究 进行展望。

\section{1 林冠塔吊站点与网络}

\section{1 塔吊结构与特征}

塔吊由铁塔塔身, 起重臂, 平衡装置, 司机操 作室和挂钩及其吊篮设备等主要部件构成(Parker et al., 1992) (图1)。根据研究需要, 塔身可以安装在固 定的底座上成为固定塔吊, 也可以安装在沿铁轨运 


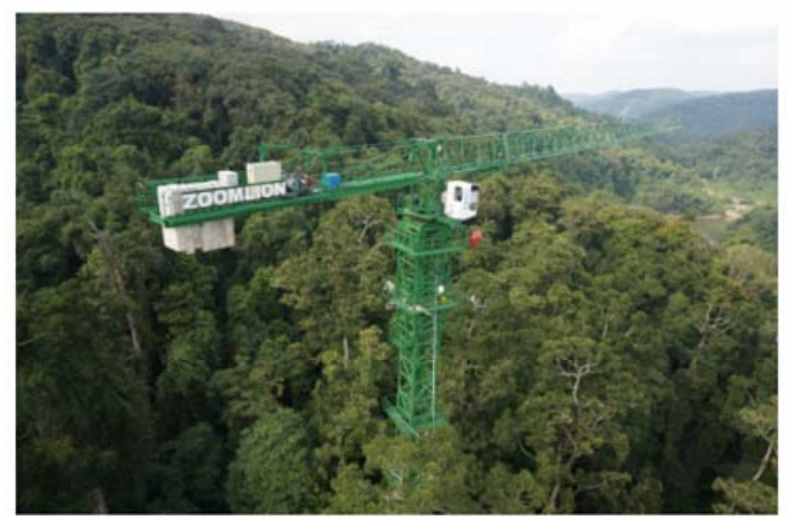

图1 云南省预腊县龙脑香热带雨林中的林冠塔吊(邓云摄)。 Fig. 1 Canopy crane in tropical dipterocarp rainforest in Mengla County, Yunnan Province (Photographed by DENG Yun).

行的移动底座上, 成为移动塔吊, 从而扩展塔吊的 有效覆盖范围(Nieder et al., 2000)。

林冠塔吊在三维空间中作业具有“全方位、高精 度、非破坏、可重复” 的特征(Schmit-Neuerburg, 2002)。训练有素的塔吊司机操控起重臂的旋转和吊 篮的升降, 可以将吊篮中的研究人员或仪器装备精 确地投放至林冠空隙间的绝大部分位置(Parker et al., 1992)。这种方式允许研究人员接近枯枝或枯木 的树梢、树冠外层枝叶或其他不适合攀爬的树木。 此外, 塔吊可以避免马蜂、蚂蚁、蛇或其他有害昆 虫对林冠作业的干扰。林冠塔吊以非入侵的方式让 研究者的重量不接触树木本身, 将爬树对树木产生 的负面影响(如将附生植物从枝条基质上剥离、折断 枝条、干扰无脊椎动物等)降到最低(Lowman \& Rinker, 2004)。

与其他进入林冠的方式相比, 林冠塔吊提供从 上到下的独特研究视角, 解决了许多因设备和人员 不能到达林冠而无法开展的研究难题。这使得研究 者能够轻松地将高层的林冠组分和生态过程纳入研 究范畴, 在三维空间内对树木个体、枝条和叶、花、 果及其林冠动物等进行重复取样, 史无前例地开展 林冠控制和观察试验, 直接测量并读取数据 (Pennisi, 2005)。高大乔木的生理生态、 $\mathrm{CO}_{2}$ 动态和 气候变化、生物多样性、传粉生态、物候和森林病 虫害监测等均可依托林冠塔吊进行(Stork et al., 1997)。

\section{2 国外林冠塔吊的建设和分布}

史密森尼热带研究所(Smithsonian Tropical Re- search Institute)在Alan Smith的指导下于1990年首次 将塔吊安装在巴拿马低地森林, 开创了通过塔吊研 究林冠结构和整株树木生理的先河(Parker et al., 1992; Lowman et al., 2012)。之后, 林冠塔吊陆续在 美国、委内瑞拉、澳大利亚、巴拿马、马来西亚等 地的不同森林类型中出现。截至2015年, 国外共有 11座林冠塔吊, 覆盖的森林总面积约 $11.7 \mathrm{hm}^{2}$, 其 中5座位于热带森林(Stork, 2007a; Lowman, 2009), 总面积近 $6 \mathrm{hm}^{2}$ (表1)。塔吊主要集中在欧洲(4座)和 美洲(4座), 亚洲只有2座。澳大利亚Cairns塔吊是唯 一位于南半球的塔吊。委内瑞拉Surumoni和德国 Leipzig塔吊是移动塔吊, 底座安装在120 m长可移 动的轨道上, 其余9座是固定底座的塔吊。覆盖面积 超过 $1 \mathrm{hm}^{2}$ 的塔吊有4座, 它们覆盖的森林面积之和 超过 $7 \mathrm{hm}^{2}$ 。其中, 起重臂最长的是美国Wind River 塔吊 $(85 \mathrm{~m})$, 它覆盖森林面积最大 $\left(2.3 \mathrm{hm}^{2}\right)$ 。塔身最 高的是马来西亚Lambir Hills塔吊 $(80 \mathrm{~m})$, 对应覆盖 面积1.77 $\mathrm{hm}^{2}$ 。而德国Solling和瑞士Basel塔吊臂长 最短, 覆盖森林面积最小(分别为 0.2 和 $0.28 \mathrm{hm}^{2}$ )。

由于各塔吊所处植被类型以及研究目标差异, 不同塔吊具有不同的研究主题和侧重点。在温带森 林塔吊中, 除了美国Wind River塔吊研究过附生非 维管植物外, 欧洲4座塔吊和日本北海道塔吊几乎 没有开展关于附生植物的研究。5座热带林冠塔吊中, 巴拿马Parque Metropolitano塔吊样地因附生植物稀 少而没有涉及，其余4座塔吊均将附生植物作为主 要的研究对象。上述塔吊中, 美国Wind River塔吊和 委内瑞拉Surumoni塔吊因经费或自然条件限制, 目 前已停止运行(Mitchell et al., 2002)。

\section{3 国际林冠研究组织}

单个塔吊站点的结果不具有普遍性, 对政策制 定者和资源管理者的影响力明显不足。塔吊网络可 以在若干个站点实施统一标准的试验或在不同站点 之间共享数据, 扩大研究的价值(Stork, 2001)。在此 背景下, 一些致力于林冠学研究的国际组织, 如国 际林冠塔吊网(International Canopy Crane Network, ICCN) 与全球林冠计划 (Global Canopy Program, GCP)等先后成立。这些网络试图建立一套统一的林 冠学研究方法, 收集、储存、分析、解释并可视化 展示这些三维空间数据, 服务于林冠科学家、森林 管理者和社会公众等(Nadkarni, 1993; Nadkarni et al., 1996)。 


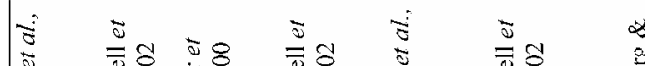

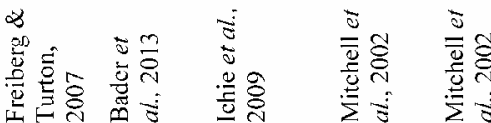

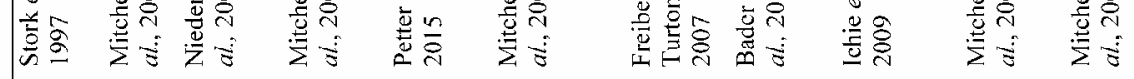

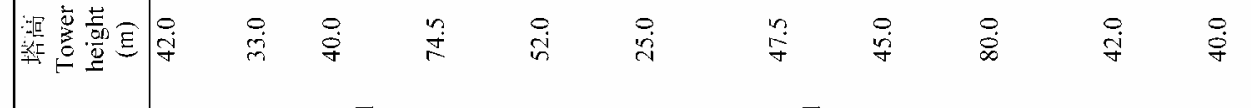

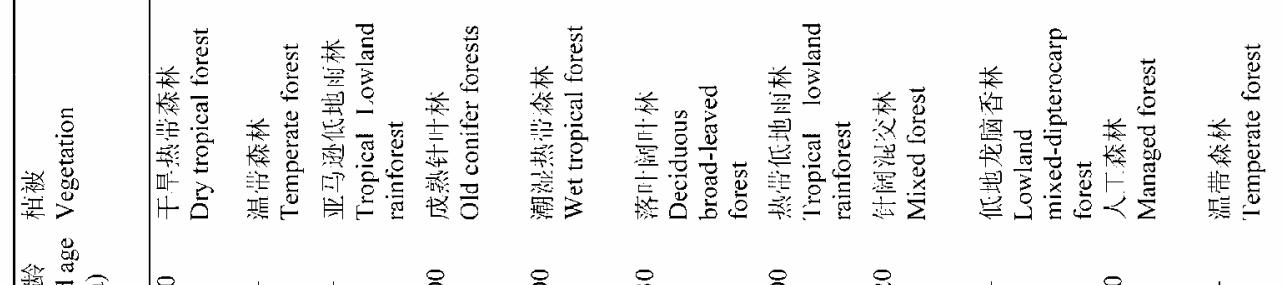

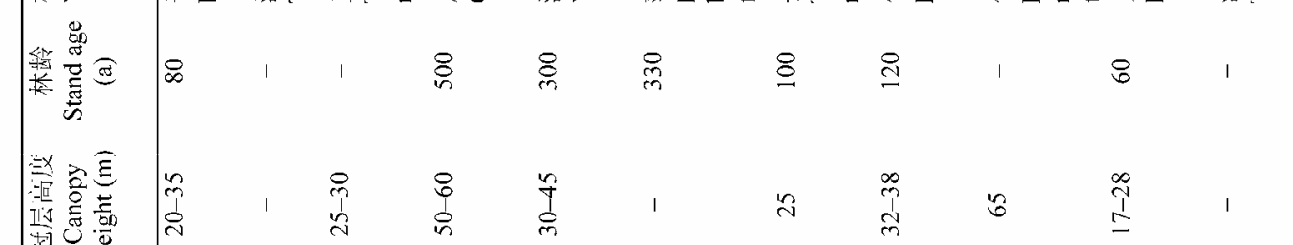




\subsection{1 国际林冠塔吊网(International Canopy Crane Network, ICCN)}

1997年3月, 在巴拿马举行的首次国际林冠塔 吊研讨会(International Canopy Crane Symposium), 将“整合研究力量, 发挥林冠塔吊研究的最大影响 力”作为其核心议题。会议决定成立国际林冠塔吊网 络。鉴于林冠塔吊作为有效工具回答全球尺度上关 键科学问题的潜在价值, 研讨会得到生物多样性公 约秘书处(Conventions on Biological Diversity)、气候 变化与臭氧层空洞委员会(Climate Change \& Depletion of the Ozone Layer)等国际组织的关注(Stork et al., 1997; Stork, 2001)。

国际林冠塔吊网是全球林冠塔吊的联盟, 旨在: (1)促进林冠塔吊研究的交流合作; (2)多个塔吊站点 长期同步监测, 为林冠结构、功能和生物多样性的 研究提供基础资料。该组织的愿景是将各塔吊站点 作为参考, 对塔吊覆盖样地林分结构制图, 形成有关 森林林冠功能及其过程的知识框架, 以便在更大空间 尺度上进行验证(Basset et al., 2003)。该网络倡导建立 数据标准化协议和数据集, 提供更为全球化的观点, 确保将林冠研究最新信息传送给政策制定者。

\subsection{2 全球林冠计划(Global Canopy Program, GCP)}

受欧洲科学基金会和美国国家科学基金会联合 资助, 国际林冠科学研讨会 (International Canopy Science Workshop)于1999年在牛津大学举行。10个 国家的29名林冠学者为全球林冠计划设定了基本框 架。该组织与ICCN联合, 计划在从温带到热带的重 要森林中安装更多的林冠塔吊(Pennisi, 2005)。该研 究计划拟跟踪监测气候变化对林冠附生植物的作用, 通过全球气候变化预测模型, 提高人们对林冠重要 性的认识(Ozanne et al., 2003; Hopkin, 2005)。

全球林冠计划关注的主要科学问题有林冠生态 系统功能、林冠生物多样性及其维持机制、全球变 化对林冠生物多样性的影响、林冠的社会经济价值 以及林冠产品和生态服务如何确保当地社区环境安 全等。其使命是将全球森林研究整合至为期10年的 研究计划, 认识林冠在生物多样性及其在气候变化 中的作用(Lowman \& Rinker, 2004)。由全世界40多 位林冠研究者汇编完成的《全球林冠手册》, 已成 为林冠研究的重要工具书(Mitchell et al., 2002)。近 年来, 该组织还提出整体森林观测(whole forest observatory)概念, 即将森林视为地下、地表、林冠三
个层次的整体结构和功能系统，对森林整体结构进 行立体的长期观测。该系统除了常规观测外, 还配 置了移动(热气球)的和静态(塔吊)的林冠观测设施, 从而开展森林不同垂直梯度上的观测研究(Lowman et al., 2013)。

由于林冠在维持区域及全球生物多样性上的重 要性, 在第三届国际林冠学大会上通过了“林冠研 究凯恩斯宣言” (Ozanne et al., 2003)。宣言强调以塔 吊为标志的林冠调查新技术, 加强林冠生物多样性 及其在维持生态系统服务功能方面的研究, 建立国际 林冠数据库和通讯网络, 将林冠附生亚系统纳入濒危 栖息地的整体保护计划。林冠塔吊及上述国际研究组 织/会议的出现表明: 作为研究林冠结构、功能及其与 土壤系统、大气系统物质循环、能量流动相互关系的 林冠科学已逐渐成为目前国际上生物多样性、全球变 化研究中的热点(Lowman \& Rinker, 2004; Lowman \& Schowalter, 2012; Lowman et al., 2013)。林冠学已成为 国际森林生态学研究的前沿, 有望逐步发展成为一门 新兴学科(宋亮和刘文耀, 2013)。

\section{2 基于林冠塔吊开展的附生植物研究进展}

\section{1 研究概况}

截至目前, 国外的11座林冠塔吊中有5座开展 过附生植物研究。归纳起来, 林冠塔吊附生植物研 究主要有以下特点:

(1)林冠塔吊在中南美洲热带低地雨林应用最 早, 覆盖面较广。其中, 在巴拿马San Lorenzo塔吊 样地开展的附生植物相关研究最具有代表性。依托 该塔吊, 德国Oldenburg大学的Gerhard Zotz教授从 叶片、种群和生态系统等不同层面集成, 致力研究 附生植物的生态问题, 取得一系列成果(Laube \& Zotz, 2006a; Zotz \& Schultz, 2008; Petter et al., 2015)。 在委内瑞拉Surumoni塔吊样地, Engwald等对附生植 物的多样性、空间分布格局及其演替进行了系统研 究, 绘制了附生植物在林冠三维空间中的地理坐标 和地图(http://www.engwald.homepage.t-online.de/ Surumoni.htm)。

史密森尼热带研究所在巴拿马先后建立了两座 林冠塔吊。第一座建成于1990年, 位于巴拿马城边 的Parque Natural Metropolitano国家公园, 主要开展 林冠物候和光合作用研究(Mitchell et al., 2002)。 1997年又在加勒比海岸的Fort Sherman (后更名为 
San Lorenzo)建立了第二座林冠塔吊。自2000年在 San Lorenzo塔吊样地启动 “热带林冠生物学计划” (Tropical Canopy Biology Program)以来, 研究成果 稳步增长。2003-2005年又开展了“土壤与林冠节肢 动物多样性调查” (Investigating the Biodiversity of Soil and Canopy Arthropods, IBISCA)项目。该项目 有 45 名工作人员从事野外工作, 16 个国家100多名科 学家鉴定物种(Basset et al., 2003)。Zotz和Schultz (2008)完成了该林冠塔吊范围内全部附生植物的调 查, 并对宿主物种名称、径级大小、附生高度、基 质/枝条直径和与主干的倾角等参数进行了详细记 录。该数据集被用作附生植物动态长期监测的基础 数据。除了对附生植物多样性和空间格局的研究之 外, 他们还进一步开展了附生植物垂直分层的生理 机制研究(Zotz \& Hietz, 2001; Petter et al., 2015)。

奥地利科学院和委内瑞拉政府联合实施了跨学 科的Surumoni林冠塔吊项目, 旨在研究新热带雨林 林冠的结构与功能。该塔吊于1995年建成, 研究样 地位于亚马孙Orinoco河及其支流Surumoni河口处 (Anhuf \& Winkler, 1999)。该项目目标是: (1)调查附 生植物物种多样性及其群落结构; (2) 探讨附生植物 动态及其影响因素; (3)构建该样地附生植物的结构 和功能的模型(Engwald et al., 2000)。项目从1995年 开始至2000年夏季结束, 分为两个阶段。第一阶段 (1995-1997年): 记录附生植物在林冠的高度、宿主 和附生植物的种类以及聚集或个体出现形式，鉴定 样地内所有附生植物物种, 对以上信息进行精确制 图, 并拍照存档。第二阶段(1998-2000年): 在前期 工作基础上, 分析影响附生植物的因子, 监测附生 植物的演替动态。附生植物空间分布的三维数据被 集成在GIS之中, 可以对物种和个体的周转率进行 比较(Schmit-Neuerburg, 2002)。

(2)亚太地区热带低地雨林塔吊样地仅各有一 篇关于干旱对鸟巢䓲(Asplenium nidus)分布的影响 以及鸟巢䓲对宿主偏好的报道。其中, 马来西亚 Lambir Hills国家公园的林冠生物学研究计划以沙 捞越和日本科学家建立的 “林冠走廊” 作为开端 (Inoue et al., 1995)。之后, 日本科技协会于2000年在 该样地内建成了林冠塔吊, 将林冠研究推进到一个 新的阶段。该塔吊研究主要关注低地龙脑香林的集 中开花和结果(mass flowering and fruiting)以及物种 共存机制等内容(Ichie et al., 2009)。澳大利亚Cairns
塔吊位于昆士兰州Daintree低地雨林的Cape Tribulation。该项目最初目标是用塔吊来测量样地树木的 形态, 基于这种测量来精确计算地上生物量及树冠 的动态变化(Liddell et al., 2007)。

该地区林冠塔吊样地内没有开展过附生植物多 样性及其空间格局的研究。其原因可能是干旱和风县 风对样地内附生植物造成严重干扰。如澳大利亚热 带气旋(tropical cyclones)对Cairns塔吊样地频繁地 灾难性破坏, 并使部分散生巨树折断, 对附生种群 产生毁灭性的影响(Laidlaw et al., 2007)。与厄尔尼 诺-南方涛动(El Niño-Southern Oscillation, ENSO)有 关的东南亚低地雨林极端干旱事件也会导致大量附 生植物死亡(Harrison, 2006; Fayle et al., 2009)。

(3)非维管附生植物的研究很少, 尽管这类植物 对附生植物的生物多样性, 甚至对整个森林生态系 统功能都有重要贡献。在11座塔吊中, 仅在美国 Wind River塔吊样地开展了附生非维管植物的垂直 分层及其成因的研究。欧洲温带森林4座塔吊很少涉 及附生植物研究(Lowman \& Rinker, 2004)。

(4)尽管国外存在过 11 个塔吊及多个林冠研究 网络组织, 但事实上不同站点间的附生植物数据共 享以及联网研究尚未开展过。截至目前, 已公开报 道的林冠附生植物研究案例都是基于单一站点的研 究结果。这种情况可能是由以下两个原因所致。首 先是亚太地区两座热带森林塔吊的设计初衷不是为 研究附生植物而建。研究初始目标不同, 导致选址 时不能兼顾附生植物的背景资料。其次, 因 Surumoni塔吊停运, 故新热带森林只剩下1座塔吊 研究附生植物。林冠塔吊在同一森林中一般只有一 座而没有空间独立的重复。因此, 在塔吊样地上进 行的观测性试验都要避免伪重复问题(Pseudo replication)(Basset et al., 2003; Lowman et al., 2013)。塔 吊网络在不同生物地理区域的比较以及大量取样有 助于解释在不同时空尺度的附生植物格局是否一致 (Stork et al., 1997)。

\section{2 具体的研究案例}

\subsection{1 附生植物多样性及其空间分布}

Surumoni塔吊样地附生植物研究是世界上首次 通过林冠塔吊对 $1.5 \mathrm{hm}^{2}$ 热带低地森林进行的最全 面调查。该样方中有 778 个个体, 属于 13 科 53 种。整 体上, $70 \%$ 物种个体数低于 10 个, 只有 5 种个体数大 于 50 个。 $51 \%$ 的个体(397/778)出现在高光照且干旱 
的林窗蚂蚁巢穴(ant nests)上, 属于专性蚂蚁花园附 生(obligate ant-garden epiphytes)。兰科物种占全部物 种数的 $37 \%$, 偋类占 $14 \%$, 体现了典型的热带低地 附生植物物种组成特征(Anhuf \& Winkler, 1999; Carlsen, 2000; Engwald et al., 2000)。在53种附生植 物中, 有36种(69\%)是专性附生, 14种(27\%)半附生, 2种(4\%)是偶然附生(Nieder et al., 2000)。不同宿主 为附生植物提供了不规则的异质性资源镶嵌基质 (Engwald et al., 2000), 附生植物在水平方向呈集群 分布。蚂蚁对林窗的偏好促使半数以上的蚂蚁花园 附生出现在林窗周围。半附生喜林芋属(Philodendron)的根系或茎与地面连接, 它们的分布更均匀。附 生植物水平和垂直生态位可能存在广泛重叠, 森林 镶嵌(forest mosaic)的随机动态允许生态位类似的 附生物种共存(Nieder et al., 2000)。

巴拿马San Lorenzo塔吊样地共记录103种附生 维管植物, 13099 个体。物种和个体数量上, 兰科都 是最重要的科, 占物种数量的 $40 \%$ 以上, 占全部个 体的 50\%以上。在中等高度, 物种有一个明显的垂 直集中(vertical segregation)现象: $50 \%$ 以上的个体出 现在地面以上 15 至 $25 \mathrm{~m}$ 之间。乔木种类、径级大小 以及树木在林分中的空间位置三个因素都影响附生 植物的物种组成。但典范对应分析(CCA)发现, 没有 两个环境变量或空间因素能单独解释附生植物组合 $10 \%$ 以上的总变异。到目前为止, 大部分观察到的 变异仍然无法解释, 可能主要受随机因素的影响 (Zotz \& Schultz, 2008)。因繁殖体扩展限制, 附生植 物多显示为集群分布。即附生植物在同一宿主上散 播的种子比宿主间的更多, 导致少数物种的大量个 体出现在同一宿主个体上(Zotz \& Vollrath, 2003; Burns \& Zotz, 2010)。

垂直分布区理论在附生维管植物多样性研究中 被广泛运用。Johansson (1974)基于在西非雨林大树 的附生植物研究, 发现大多数的附生植物占据宿主 基质的特定区域，因而提出经典的Johansson分区。 利用San Lorenzo塔吊样地附生植物多样性资料进 行聚类分析和判别分析, Zotz (2007a) 在垂直方向上 提取出6种附生类群, 虽然大体上与Johansson分区 相符, 但也有一些类群(约占总物种数的 $10 \%$ )偏好 小径级树种。故单独研究大树上的附生植物不能代 表该群落的整体。因此, 源自大树/老树的垂直分区 方案可能低估附生维管植物物种多样性和多度, 将
会遗漏一些重要的空间分布信息，低估总的附生植 物多样性, 故较小径级宿主也应被包括在附生植物 多样性研究中(Krömer et al., 2007)。

在Wind River塔吊样地内40株宿主上分层随机 取样, 记录到111种附生植物, 含97种地衣14种苔藓, 但没有附生维管植物(McCune et al., 2000)。附生植 物具有明显的垂直分层现象(McCune et al., 1997)。 发状地衣(Alectorioid)集中分布在林冠最上层; 蓝藻 地衣(Cyanolichen)在中低层林冠最多, 集中在光过 渡区; 苔藓主要分布在林冠下层和枝条基部。其原 因可能是蓝藻地衣不能忍受高光和紫外线, 需要液 态水才能进行生理活动; 苔藓需要高湿度和水分, 更适合在低光潮湿的环境下生长。高大树梢最外层2 $\mathrm{m}$ 具有丰富的稀有种(Tholurna dissimilis)和嗜氮地 衣类群, 可能是因为鸟类栖息带来大量地衣繁殖体, 同时其排泄物提供了充足的养分(McCune et al., 2000)。在样地水平, 林冠高度和径级大小是影响附 生植物组成和分布的主要因子; 在宿主尺度, 基质 特性和微生境对塑造和维持附生植物多样性具有重 要影响(Lyons et al., 2000)。此外, Antoine和McCune (2004)发现局限分布在林冠中层(25-30 m)的俄勒冈 肺衣(Lobaria oregana)和肺衣(Lobaria pulmonaria)最 大生长速率出现在更高的 40-45 m处, 但现实分布中 却没有出现在上层。其原因可能是林冠上层优势种 松萝(Usnea scabrata)竞争排斥了前者, 这意味着基 础生态位和现实生态位的差异受种间竞争的影响。

\subsection{2 附生植物与蚂蚁的互惠关系}

蚂蚁花园是新热带低地雨林林冠中的特有景 观。该景观由蚂蚁和附生植物所形成的紧密的共生 关系建立和维持(José Ibrahin, 2004)。蚂蚁花园内的 主要关系是: (1)蚂蚁巢穴为附生植物提供稳定的生 长基质, 筑巢过程传播附生植物种子和蓝藻细菌; (2)附生植物不定根给蚁穴结构性支撑, 细根从蚁巢 沉积物和蓝藻细菌中获得养分; (3)蓝藻细菌也从根 系分泌物和蚂蚁碎屑中进行碳循环(Cedeño et al., 1999)。Surumoni塔吊样地附生植物花外蜜腺和蚂蚁 丰度有密切关系。天南星科喜林芋属的花外蜜腺是 林冠蚂蚁的主要食物来源(Bluthgen et al., 2000)。此 外, 蚂蚁及其基质对附生植物 Peperomia macrostachya 和其他附生植物适合度和存活具有积极作 用(Schmit, 2007)。进一步研究发现, 去除蚂蚁后为 期两月的干旱导致附生基质干旱疏松, 最外层逐步 
消失，附生植物幼苗枯萎且大量幼苗从基质上消 失。当蚂蚁和基质都去除时, 成年的附生植物的开 花或结实均受到影响。因此, 在干季蚂蚁可为附生 植物提供稳定基质和水分。

Maruyama等(2014)在马来西亚Lambir Hills塔吊 样的附生蕨类(Platycerium crustacean)内举腹蚁属 (Crematogaster)蚁穴中发现了喜蚁的(myrmecophilous) 鞘翅目雉象鼻虫科(Brentidae)新属(Pycnotarsobrentus)。 但它们与蚂蚁和附生鳜三者间的关系有待进一步研 究。

\subsection{3 附生植物的种群动态}

群落生态的中心问题是掌握种群动态, 即推测 群落物种组成过去变化, 预测将来物种组成 (Crawley, 1997)。在全球变化背景下, 附生植物的长 期动态监测便显得尤为重要。Laube和Zotz (2006a) 运用San Lorenzo塔吊, 对该样地内的附生植物动态 进行了长期系统的监测, 结果表明在 5 年时间内该 样地内整体附生植物组成基本稳定, 尽管单个宿主 上的附生植物有一定的动态变化。附生植物死亡率 较大, 即使长势良好的类群经历 5 年后也只剩下 $46 \%$ 的个体。此外, 利用附生维管植物的信息, 用当前的 种群增长来推断将来组成变化。Zotz (2007b)预测, 常见附生种可能增加, 稀有种则依赖于其他种群的 迁移, 可能在当地会存活下来。这意味着当地附生 植物种群大小与种群等级结构具有重要关系。

澳大利亚Cairns塔吊样地内共有102株鸟巢蕨。 其中75株在林冠层, 4株在地面卵石上, 23株生长在 地面上。连续四周的干旱无雨, 腐殖质完全干燥, 可 以导致大量鸟巢蕨死亡并从树上调落。此外, 通过 对样地内全部鸟巢葓种群分析, 发现最老的个体起 源于1985年。其原因可能是1984年的干旱导致样地 内几乎全部的鸟巢蕨死亡。在全球变暖背景下, 该 样地内鸟巢䓲的多度可能逐步降低, 其分布范围将 限制在林冠下层。这将对与鸟巢葓有关的林冠动物 产生类似作用(Freiberg \& Turton, 2007)。

\subsection{4 附生植物的宿主偏好}

宿主专一性程度是研究附生植物生态学的基 础。自从Schimper关于附生植物生态学的经典著作 于19世纪问世后已有200多篇文献研究附生植物的 宿主专一性(Wagner et al., 2015)。Zotz等基于巴拿马 San Lorenzo塔吊, 研究了附生维管植物的宿主专 一。研究发现, 膜硕科(Hymenophyllaceae)喜欢附生
于大树/老树。其原因可能是大树具有厚树皮且持水 量更高, 更利于附生植物的建群和生长。另外, 大树 为附生植物繁殖体提供定居的时间也更久(Zotz \& Buche, 2000)。通过模拟附生植物零模型在森林中的 随机分布，发现3种宿主上的大多数(69\%-81\%)附 生植物都是随机分布; 而剩余物种或者过多或不足 代表随机分布。尽管一些附生物种特别偏好特定的 物种, 但这种偏好并不局限单一宿主。故某一宿主 上出现的附生植物, 既不是简单的随机出现, 也没 有出现绝对专一性偏好(Laube \& Zotz, 2006b)。整体 上, 附生植物的宿主范围很大程度上是自由选择而 不受约束, 但存在一些宿主偏好现象(Wagner et al., 2015)。

马来西亚Lambir Hills塔吊样地内, 鸟巢蕨从不 同宿主上获得物理支撑，对宿主树皮质地没有偏 好。但是鸟巢硕的大小与宿主的胸径显著相关, 大 鸟巢蕨位于较大胸径的宿主上, 可能与鸟巢硕需要 更大的表面积、更稳定的小生境和更长的建群时间 有关(Rajapakse et al., 2004)。

\subsection{5 附生植物光合途径}

景天酸代谢(crassulacean acid metabolism, CAM) 特征是夜间固碳并在液泡中积累有机酸, 通过PEP 脱羧反应, 白天气孔关闭(Silvera et al., 2009)。不少 附生维管植物以CAM光合途径应对干旱, 水分利 用效率高(Adibah \& Ainuddin, 2011)。Zotz (2004)在 San Lorenzo塔吊样地中发现有20种CAM物种(占总 数的 $19.4 \%$ ), 主要是兰科、风梨科和仙人掌科。由 于CAM类型在微小或稀有的兰科中普遍存在, 以 个体数或生物量来推测附生植物中CAM的重要性 与从物种数得到的结果将会有很大不同。

\section{3 附生植物研究重点领域}

\section{1 附生植物多样性}

生物多样性及其成因是生态学的核心内容 (Kalyuzhny et al., 2015), 也是维持生态系统稳定性, 确定优先保护的关键(Hautier et al., 2015)。它已成为 人类在未来 $1 / 4$ 世纪里最具挑战性的 125 个科学问题 之一(Kennedy \& Norman, 2005)。林冠被视为是最后 的生物前沿, 公众对之知之甚少。看似最简单的问 题, 如不同树种或不同森林类型林冠附生植物有多 少, 它们的资源库和生态位是怎样的, 等等诸多问 题仍未得到满意的答复(Basset et al., 2003)。尽管朱 
华(2000)对龙脑香低地雨林的附生植物进行过研究, 但是基于地面观察技术所获得的相关信息对龙脑香 热带雨林而言只是冰山一角。该群落中的望天树是 新热带低地雨林冠层高度的两倍, 光照、温度与水 分可用性沿垂直梯度剧烈变化(Szarzynski \& Anhuf, 2001), 为附生植物提供了高异质性小生境(Bartels \& Chen, 2012)。但因没有林冠塔吊的支撑, 分布于 这类森林中的附生植物多样性长期被忽略。

此外, 附生维管和非维管植物的研究是分开进 行的, 鲜有不同附生类群间的综合对比(Kelly et al., 2004)。不同类群附生植物的多样性格局在不同森林 中有何差异? 林冠塔吊以及林冠塔吊联网能有针对 性地回答生物多样性保护和利用中的林冠层“有什 么? 在哪里? ”等问题(马克平, 2014)。

\section{2 附生植物的空间格局和维持机制}

林冠生物的空间格局受到水平(不同宿主) (Wagner et al., 2015)、垂直(分层)(Li et al., 2015)和时 间(物候变化)(Einzmann et al., 2014)等因子的影响。 林冠塔吊提供了更精细的观测平台, 生物体的空间 分布成为林冠塔吊研究的重点之一(Basset et al., 2003)。已有的研究发现, 新热带附生植物多样性及 群落格局有不同解释。如在委内瑞拉Surumoni塔吊 样地内, 完全附生植物(holo epiphytes)在水平方向 上呈聚集分布; Tillandsia paraensis的垂直分布很大 程度上由其生理机制及其对光照的需求决定。与繁 殖体扩散方式相比, 基质可用性是附生植物建立和 生长的更重要因子(Nieder et al., 2000)。但是在巴拿 马San Lorenzo塔吊样地, 短距离传播却是附生植物 集群分布的重要原因。即因繁殖体扩展限制, 附生 植物在同一宿主上散播得比宿主间更多, 导致少数 物种的大量个体出现在同一宿主个体上(Zotz \& Vollrath, 2003)。最近, Woods等(2015)发现哥斯达黎 加低地雨林中胸径最大的肉豆冦科散生巨树Virola koschnyi具有最丰富的林冠小生境和附生植物多样 性, 支持“小生境多样性和专一性塑造热带附生群 落” 的观点。因此, 尽管对热带乔木多样性的研究已 经取得了很大进步(Hu et al., 2012), 但附生植物多 样性维持机制研究却很患乏, 有必要通过林冠塔吊 在不同时空尺度上进行高精度的观察和实验 (Wagner et al., 2015)。

\section{3 附生植物的生态适应性}

与多数地生生境相比, 附生生境养分受限并呈
斑块状分布，光照更强、温度更高但湿度更低 (Cardelus, 2010; Testo \& Sundue, 2014)。附生植物具 备一系列适应林冠生境的特征。如叶片具有旱生构 造; 光保护能力强、能避免或者忍受干旱(如CAM光 合途径)(Zotz \& Hietz, 2001); 通过表皮毛或叶片吸 收水分和养分, 提高了水分和养分的吸收能力; 繁 殖体/种子小但数量多(Benzing, 2004)。如附生兰属 (Cymbidium) 植物叶片肉质化程度更高, 组织储水 能力更强, 使植物体内的水分平衡和生理功能在水 分胁迫时维持更长时间(Zhang et al., 2015)。兼性附 生蕨类(Selliguea griffithiana) 通过克隆整合作用 (clonal integration)维持在林冠生境中的存活与生长, 附生种群的整合作用比地生种群的更大(Lu et al., 2015)。上述生理机制能提高附生植物对林冠胁迫环 境的适应。此外, 附生植物叶片功能性状沿着环境 垂直梯度隔离而有利于生态位分化(Petter et al., 2015)。如共存于同一生境中的两种舌硕属(Elaphoglossum)植物, E. herminieri的比叶面积 (SLA) 比E. latifolium低, 且倒垂悬挂在横向光照更高的枝条下 面，后者在宿主枝条顶部向上生长(Woods, 2013)。 因此, 在水分和养分受限的林冠生境中, 附生植物 为植物生理生态研究提供了独特的实验材料。通过 塔吊研究附生植物的生态适应性, 有助于阐明附生 植物占据林冠生态位过程中物种形成和多样性维持 的原因(Gravendeel et al., 2004; Bartels \& Chen, 2012; Givnish et al., 2015)。

\section{4 附生植物与林冠动物的关系}

附生基质的异质性和资源镶嵌分布通常产生各 种互惠关系(如蚂蚁花园附生), 使林冠生物之间的 相互关系更为复杂。但是大多数林冠生物及其与林 冠生境的相互关系都是未知的(Basset et al., 2003; Ruano-Fajardo et al., 2014)。以东南亚低地龙脑香林 为例, 龙脑香林间隔2-7年的“集中开花/结果”格局, 塑造了亚洲热带雨林的基本生态学过程。在短暂的 “盛宴”与漫长的 “饥荒” 交替中, 林冠附生植物提供 的花蜜/蜜腺、果实等成为林冠动物度过 “饥荒” 的极 其重要的食物资源(Corlett \& Primack, 2011)。此外, 附生植物提供的阴凉潮湿的生境还是位于干燥高温 的林冠层动物的重要栖息地。鸟巢蒝最大个体鲜质 量可以达到 $200 \mathrm{~kg}$, 能为 41000 头无脊椎动物提供 栖息地(Ellwood et al., 2002)。一株大鸟巢硕所维系 的无脊椎动物生物量相当于该树冠内其余所有鸟巢

www.plant-ecology.com 


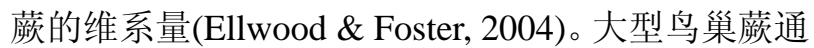
过创造小生境并改善环境条件, 成为树蛙活动和繁 育的重要场所, 其生态作用不容忽视(Scheffers et al., 2014)。通过塔吊在林冠层开展原位动植物相互 关系研究, 可以揭示附生植物作为林冠动物食物镶 嵌体和庇护所以及林冠动物对附生植物空间分布的 影响, 进一步加深对林冠系统生态过程的认识。

\section{5 附生植物对气候变化的响应}

附生植物不能从地面资源库获取水分和矿质养 分, 而主要依赖于空气输入, 被认为对全球气候变 化(如增温、湿度降低或降水减少)特别敏感(Gotsch et al., 2015), 适于作为研究气候变化的指示物(Zotz \& Bader, 2009)。雾形成的隐匿(occult)或水平降水 (horizontal precipitation), 其可用性可能超过垂直降 水, 成为干季附生植物的主要水源(Gotsch et al., 2015)。长期观测(Pounds et al., 1999)和模型推演 (Still et al., 1999)发现热带低地土地利用/土地覆盖 变化导致雾凝结高度抬升(lifting condensation level), 即云底上升(lifting cloud base), 使邻近山地云雾林 雾持续时间和频率减少、雾强度降低(Lawton et al., 2001), 并已导致部分脆弱的附生植物从一些受威 胁森林中消失(Zhu et al., 2010)。在西双版纳, 因橡 胶林导致的土地利用变化(Li et al., 2008)、区域气候 干热化(Fan et al., 2011)以及森林片段化(Negret et al., 2013)引发雾日和雾时缩短、雾量减少(Liu et al., 2014)。生境逐渐由凉湿向干暖转变(兰国玉等, 2010), 喜湿耐阴的附生植物减少(梁娟等, 2007; Zhu et al., 2010)。云雾格局变化对一些敏感物种可能产生毁灭 性后果(Bruijnzeel et al., 2011)。在此背景下, 开展典 型附生植物的人工模拟实验, 研究雾对附生植物碳水分平衡关系的影响, 预测附生植物种群分布格局 和生长繁殖对云雾格局变化的响应具有重要意义。

\section{4 我国附生植物研究与林冠塔吊建设现状}

国内林冠附生植物的研究虽起步较晚，但近年 来我国学者在附生植物多样性与分布格局(徐海清 和刘文耀, 2005; Ma et al., 2009; 刘广福等, 2010a, 2010b)、群落结构(Zhao et al., 2015)、叶片形态结构 及生态适应性(江浩等, 2012; Zhang et al., 2015)等方 面进行了一系列研究工作。中国科学院西双版纳热 带植物园刘文耀研究员的研究团队以森林生态系统 对环境变化的应对机制为目标, 利用附生植物对环
境变化敏感的特性, 研究附生植物类群对环境变化 的响应机制以及在生态恢复、演替过程中的生物指 示作用, 探讨利用附生植物监测气候变化对山地森 林生态系统初期影响及其相关的监测方法和技术。 最近在云南哀牢山湿性常绿阔叶林的研究发现氮污 染加剧将是附生苔藓的潜在威胁(Song et al., 2012a); 气候干热化将抑制附生非维管植物的光合作用和生 长(Song et al., 2015b), 使其健康状况恶化(Song et al., 2012b), 降低其生物多样性(Song et al., 2015a); 森林受损后, 林内附生植物比陆生植物更难恢复 (Song et al., 2011)。对附生地衣而言，原生林和斑块 状次生林的镶嵌分布可提高附生地衣的多样性( $\mathrm{Li}$ et al., 2011, 2013b); 树干附生地衣可作为环境变化 的指示者(Li et al., 2013a)。

以上研究大都局限于树干的 $0-2 \mathrm{~m}$ 范围内(即伸 直手臂能够得着的高度)(Song et al., 2011; 李苏等, 2015)或破坏性取样(Chen et al., 2010)。调查新近倒 木和攀爬方式(Li et al., 2015)、地面望远镜观察(刘 广福等, 2010a, 2010b)可能低估物种丰富度和多度 (Zotz, 2007a)。对于小枝和林冠外层的附生植物种群 动态、高精度的多样性组成、空间分布及其维持机 制、与林冠动物的关系等内容则无法开展。

中国科学院有关单位已分别在吉林长白山(温 带针阔混交林)、湖南八大公山(亚热带常绿落叶阔 叶混交林)、广东鼎湖山(南亚热带低地常绿阔叶林) 以及云南西双版纳斑马山(热带季节雨林)和哀牢山 (亚热带中山湿性常绿阔叶林)建成了5座林冠塔吊。 此外, 在云南丽江玉龙雪山(亚高山针叶林)、浙江古 田山(亚热带常绿阔叶林)还有2座林冠塔吊正在建 设或规划中(曹敏, 林冠生态学与生物多样性研讨 会)。其中, 西双版纳塔吊吊篮工作高度达81 m (生 态站实测数据)。邻近塔吊样地还有林冠空中走廊可 作为辅助观察设施。这使得西双版纳塔吊有可能成 为亚太地区现有 3 座热带林冠塔吊中最有利于开展 附生植物研究的平台, 并可以与新热带巴拿马塔吊 样地的研究结果进行比较。而刚建成的哀牢山林冠 塔吊则是当前世界上海拔最高的塔吊。据不完全统 计, 云南哀牢山湿性常绿阔叶林有附生植物超过 500种(Song \& Liu, 2013), 丰富的附生植物多样性 为基于塔吊的林冠附生植物研究提供了良好条件。 另一方面, 仅云南省就将建设3座林冠塔吊, 分别代 表热带雨林、亚热带常绿榈叶林和亚高山针叶林3 
种森林类型。这为立足不同森林类型开展具有区域 特色的研究以及为我国规范统一、可比较的林冠生 物学联网研究奠定了基础。

\section{5 展望}

综上所述, 林冠塔吊为附生植物的前瞻性探索 提供了契机, 这使得对林冠附生植物多样性和空间 结构的高分辨率研究成为可能(Nieder et al., 2000; Zotz \& Schultz, 2008)。塔吊的出现可以突破林冠高度 的物理限制, 林冠已不再高不可及。但作为最后的 生物前沿, 人们对林冠生物多样性及其生态过程的 科学探索才刚起步(Stork, 2001; Lowman et al., 2013)。

近年来, 我国在不同的森林生态系统中已建成 5 座林冠塔吊, 另有2座正在建设当中, 这些塔吊将 成为未来我国林冠研究的重要支撑设施。为了高效 利用已经建立的塔吊资源, 充分发挥塔吊在林冠研 究中的作用, 2015年10月, 中国科学院西双版纳热 带植物园举办了 “林冠生态学与生物多样性国际学 术研讨会”。德国Leipzig塔吊负责人Martin Freiberg, 马来西亚Lambir Hills塔吊负责人Takao Itioka、第七 届国际林冠学大会主办人Claire Ozanne以及澳大利 亚Griffith大学的 Roger Kitching 和捷克科学院的 Vojtech Novotny等林冠科学家与会。来自美国、德 国、澳大利亚、英国、日本等 10 个国家和地区的 50 多位国内外同行交流了林冠科学研究中的新成果、

新技术，探讨了将来开展合作研究的机遇和设想。

中国科学院生物多样性委员会在“十三五”规划 提出建设“中国生物多样性监测与研究网络” (Sino BON)。其中 “林冠生物多样性监测专项网” 作为 10 个专项网之一, 强调“以森林塔吊为主要平台, 开展 地带性森林林冠生物多样性的调查与监测” (马克 平, 2015)。林冠专项网将提供我国常见森林植被类 型附生植物组成和分布的长期监测数据, 为评估我 国不同类型森林生态系统附生植物多样性和空间格 局提供第一手资料, 为揭示全球变化对典型森林生 态系统附生植物的影响提供基础数据。

基金项目 云南省应用基础研究计划面上项目 (2014FB184)、国家自然科学基金-云南省联合基金 (U1133605)、国家自然科学基金(31300382)和中国 科学院青年创新促进会专项经费(2014356)。

致谢 感谢中国科学院西双版纳热带雨林生态系 统研究站邓晓保高级工程师和董金龙助理工程师在
使用林冠塔吊上给予的帮助, 感谢邓云助理研究员 提供塔吊的无人机航拍相片。

\section{参考文献}

Adibah MR, Ainuddin A (2011). Epiphytic plants responses to light and water stress. Asian Journal of Plant Sciences, 10(2), 97-107.

Anhuf D, Winkler H (1999). Geographical and ecological settings of the Surumoni-crane-project (Upper Orinoco, Estado Amazonas, Venezuela). Anzeiger, 135, 3-23.

Antoine ME, McCune B (2004). Contrasting fundamental and realized ecological niches with epiphytic lichen transplants in an old-growth Pseudotsuga forest. The Bryologist, 107, 163-172.

Bader MKF, Leuzinger S, Keel SG, Siegwolf RTW, Hagedorn F, Schleppi P, Korner C (2013). Central European hardwood trees in a high- $\mathrm{CO}_{2}$ future: Synthesis of an 8-year forest canopy $\mathrm{CO}_{2}$ enrichment project. Journal of Ecology, 101, 1509-1519.

Bartels SF, Chen HYH (2012). Mechanisms regulating epiphytic plant diversity. Critical Reviews in Plant Sciences, 31, 391-400.

Basset Y, Horlyck V, Wright SJ (2003). Studying Forest Canopies from Above: The International Canopy Crane Network. Smithsonian Tropical Research Institute, Ancon, Republic of Panama.

Batke S (2012). Epiphytes: A study of the history of forest canopy research. The Plymouth Student Scientist, 5, 253-268.

Benzing DH (2004). Vascular epiphytes. In: Lowman MD, Rinker HB eds. Forest Canopies. 2nd edn. Springer Verlag, Berlin.

Benzing DH (2012). Air Plants: Epiphytes and Aerial Gardens. Cornell University Press, New York.

Bluthgen N, Verhaagh M, Goitia W, Jaffe K, Morawetz W, Barthlott W (2000). How plants shape the ant community in the Amazonian rainforest canopy: The key role of extrafloral nectaries and homopteran honeydew. Oecologia, 125, 229-240.

Bruijnzeel L, Mulligan M, Scatena FN (2011). Hydrometeorology of tropical montane cloud forests: Emerging patterns. Hydrological Processes, 25, 465-498.

Burns KC, Zotz G (2010). A hierarchical framework for investigating epiphyte assemblages: Networks, metacommunities, and scale. Ecology, 91, 377-385.

Cardelus CL (2010). Litter decomposition within the canopy and forest floor of three tree species in a tropical lowland rain forest, Costa Rica. Biotropica, 42, 300-308.

Carlsen M (2000). Structure and diversity of the vascular epiphyte community in the overstory of a tropical rain forest in Surumoni, Amazonas State, Venezuela. Selbyana, 21, 7-10.

Cedeño A, Mérida T, Zegarra J (1999). Ant gardens of Surumoni, Venezuela. Selbyana, 1, 125-132.

Chen L, Liu WY, Wang GS (2010). Estimation of epiphytic

www.plant-ecology.com 
biomass and nutrient pools in the subtropical montane cloud forest in the Ailao Mountains, south-western China. Ecological Research, 25, 315-325.

Corlett RT, Primack RB (2011). Tropical Rain Forests An Ecological and Biogeographical Comparison. 2nd edn. Wiley-Blackwell, Oxford, UK.

Crawley MJ (1997). Plant Ecology. Blackwell Scientific, Oxford, UK.

Einzmann HJR, Beyschlag J, Hofhansl F, Wanek W, Zotz G (2014). Host tree phenology affects vascular epiphytes at the physiological, demographic and community level. $A o B$ Plants, doi: 10.1093/aobpla/pluo73.

Ellwood MDF, Foster WA (2004). Doubling the estimate of invertebrate biomass in a rainforest canopy. Nature, 429, 549-551.

Ellwood MDF, Jones DT, Foster WA (2002). Canopy ferns in lowland dipterocarp forest support a prolific abundance of ants, termites, and other invertebrates. Biotropica, 34, 575-583.

Engwald S, Schmit-Neuerburg V, Barthlott W (2000). Epiphytes in Rain Forests of Venezuela-Diversity and Dynamics of A Biocenosis. Proceedings of the First Symposium by the AFW Foundation, Hoheneim.

Fan ZX, Bräuning A, Thomas A, Li JB, Cao KF (2011). Spatial and temporal temperature trends on the Yunnan Plateau (Southwest China) during 1961-2004. International Journal of Climatology, 31, 2078-2090.

Fayle TM, Chung AYC, Dumbrell AJ, Eggleton P, Foster WA (2009). The effect of rain forest canopy architecture on the distribution of epiphytic ferns (Asplenium spp.) in Sabah, Malaysia. Biotropica, 41, 676-681.

Freiberg M, Turton SM (2007). Importance of drought on the distribution of the birds nest fern, Asplenium nidus, in the canopy of a lowland tropical rainforest in north-eastern Australia. Austral Ecology, 32, 70-76.

Givnish TJ, Spalink D, Ames M, Lyon SP, Hunter SJ, Zuluaga A, Cameron KM (2015). Orchid phylogenomics and multiple drivers of their extraordinary diversification. Proceedings of the Royal Society B: Biological Sciences, 282, $1-10$.

Gotsch SG, Nadkarni N, Darby A, Glunk A, Dix M, Davidson K, Dawson TE (2015). Life in the treetops: Ecophysiological strategies of canopy epiphytes in a tropical montane cloud forest. Ecological Monographs, 85, 393-412.

Gravendeel B, Smithson A, Slik FJ, Schuiteman A (2004). Epiphytism and pollinator specialization: Drivers for orchid diversity? Philosophical Transactions of the Royal Society B: Biological Sciences, 359, 1523-1535.

Harrison R (2006). A severe drought in Lambir Hills National Park. Ecological Studies, 51-64.

Hautier Y, Tilman D, Isbell F, Seabloom EW, Borer ET, Reich PB (2015). Anthropogenic environmental changes affect ecosystem stability via biodiversity. Science, 348, 336- 340.
Hopkin M (2005). Biodiversity and climate form focus of forest canopy plan. Nature, 436, 452.

Hu YH, Lan GY, Sha LQ, Cao M, Tang Y, Xu DP (2012). Strong neutral spatial effects shape tree species distributions across life stages at multiple scales. PLOS ONE, 7(5), e38247. doi: 10.1371/journal.pone.0038247.

Ichie T, Itioka T, Itoh A (2009). Lambir Hills National Park (Malaysia)(From field research sites (12)). Japanese Journal of Ecology, 59, 227-232.

Inoue T, Yumoto T, Hamid AA, Seng LH, Ogino K (1995). Construction of a canopy observation system in a tropical rainforest of Sarawak. Selbyana, 16, 100-111.

Jiang H, Huang YH, Zhou GY, Hu XY, Liu SZ, Tang XL (2012). Acclimation in leaf morphological and eco-physiological characteristics of different canopy-dwelling epiphytes in a lower subtropical evergreen broad-leaved forest. Plant Science Journal, 30, 250-260. (in Chinese with English abstract) [江浩, 黄钰辉, 周国逸, 胡晓颖, 刘世 忠, 唐旭利 (2012). 亚热带常绿阔叶林冠层附生植物叶 片形态结构及生理功能特征的适应性研究. 植物科学 学报, 30, 250-260.]

Johansson D (1974). Ecology of Vascular Epiphytes in West African Rain Forest. Uppsala University, Uppsala, Sweden.

José Ibrahin HR (2004). Characteristics of canopy plant substratum in a low land humid tropical forest (Upper Orinoco, Venezuela). Acta Científica Venezolana, 55, 35-43.

Kalyuzhny M, Kadmon R, Shnerb NM (2015). A neutral theory with environmental stochasticity explains static and dynamic properties of ecological communities. Ecology Letters, 18, 572-580.

Kelly DL, O’Donovan G, Feehan J, Murphy S, Drangeid SO, Marcano-Berti L (2004). The epiphyte communities of a montane rain forest in the Andes of Venezuela: Patterns in the distribution of the flora. Journal of Tropical Ecology, 20, 643-666.

Kennedy D, Norman C (2005). What don't we know? Science, 309, 78-102.

Kromer T, Acebey A, Kluge J, Kessler M (2013). Effects of altitude and climate in determining elevational plant species richness patterns: A case study from Los Tuxtlas, Mexico. Flora, 208, 197-210.

Krömer T, Kessler M, Gradstein SR (2007). Vertical stratification of vascular epiphytes in submontane and montane forest of the Bolivian Andes: The importance of the understory. Plant Ecology, 189, 261-278.

Laidlaw M, Kitching R, Goodall K, Small A, Stork N (2007). Temporal and spatial variation in an Australian tropical rainforest. Austral Ecology, 32(1), 10-20.

Lan GY, Chen W, Tao ZL, Xie GS, Lin WF (2010). A comparison study on the tropical dipterocarp rain forests of Hainan and Xishuangbanna. Acta Botanica BorealiOccidentalia Sinica, 30, 806-812. (in Chinese with Eng- 
lish abstract) [兰国玉，陈伟，陶忠良，谢贵水，林位夫 (2010). 海南与西双版纳龙脑香热带雨林比较研究. 西 北植物学报, 30, 806-812.]

Laube S, Zotz G (2006a). Long-term changes of the vascular epiphyte assemblage on the palm Socratea exorrhiza in a lowland forest in Panama. Journal of Vegetation Science, 17, 307-314.

Laube S, Zotz G (2006b). Neither host-specific nor random: Vascular epiphytes on three tree species in a Panamanian lowland forest. Annal of Botany, 97, 1103-1114.

Lawton RO, Nair US, Pielke SR, Welch RM (2001). Climatic impact of tropical lowland deforestation on nearby montane cloud forests. Science, 294, 584-587.

Li S, Liu WY, Shi XM, Liu S, Hu T, Huang JB, Wu CS (2015). Responses of the distribution of four epiphytic cyanolichens to habitat changes in subtropical forests. Chinese Journal of Plant Ecology, 39, 217-228. (in Chinese with English abstract) [李苏, 刘文耀, 石贤萌, 柳帅, 胡涛, 黄俊彪, 武传胜 (2015). 亚热带森林系统4种附生蓝藻 地衣的分布及对生境变化的响应. 植物生态学报, 39, 217-228.]

Li HM, Ma Y, Aide TM, Liu WJ (2008). Past, present and future land-use in Xishuangbanna, China and the implications for carbon dynamics. Forest Ecology and Management, 255, (1), 16-24.

Li S, Liu WY, Wang LS, Ma WZ, Song L (2011). Biomass, diversity and composition of epiphytic macrolichens in primary and secondary forests in the subtropical Ailao Mountains, SW China. Forest Ecology and Management, 261, 1760-1770.

Li S, Liu WY, Li DW (2013a). Bole epiphytic lichens as potential indicators of environmental change in subtropical forest ecosystems in southwest China. Ecological Indicators, 29, 93-104.

Li S, Liu WY, Li DW (2013b). Epiphytic lichens in subtropical forest ecosystems in southwest China: Species diversity and implications for conservation. Biological Conservation, 159, 88-95.

Li S, Liu WY, Li DW, Song L, Shi XM, Lu HZ (2015). Species richness and vertical stratification of epiphytic lichens in subtropical primary and secondary forests in southwest China. Fungal Ecology, 17, 30-40.

Liang J, Zhu H, Wang H, Zhou SS (2007). Changes in species diversity of Parashorea forest in the past 20 years in Xishuangbanna, Yunnan. Chinese Journal of Applied and Environmental Biology,13, 609-614. (in Chinese with English abstract) [梁娟, 朱华, 王洪, 周仕顺 (2007). 西 双版纳补蚌地区望天树林近 $20 \mathrm{a}$ 来物种多样性变化研 究. 应用与环境生物学报, 13, 609-614.]

Liddell MJ, Nieullet N, Campoe OC, Freiberg M (2007). Assessing the above-ground biomass of a complex tropical rainforest using a canopy crane. Austral Ecology, 32,
43-58.

Liu GF, Ding Y, Zang RG, Xu YY, Lin C, Li XC (2010a). Diversity and distribution of vascular epiphytes in the tropical natural coniferous forest of Hainan Island, China. Chinese Journal of Plant Ecology, 34, 1283-1293. (in Chinese with English abstract) [刘广福, 丁易, 藏润国, 许洋瑜, 林崇, 李小成 (2010a). 海南岛热带天然针叶林附生维 管植物多样性和分布. 植物生态学报, 34, 1283-1293.]

Liu GF, Zang RG, Ding Y, Wang WY, Li RC, Chen SW, Zhou ZL (2010b). Diversity and distribution of epiphytic orchids in different types of old-growth tropical forests in Bawangling National Nature Reserve, Hainan Island, China. Chinese Journal of Plant Ecology, 34, 396-408. (in Chinese with English abstract) [刘广福, 藏润国, 丁易, 王文 毅, 李儒财, 陈少伟, 周照骊 (2010b). 海南霸王岭不同 森林类型附生兰科植物的多样性和分布. 植物生态学 报, 34, 396-408.]

Liu WJ, Li PJ, Duan WP, Liu WY (2014). Dry-season water utilization by trees growing on thin karst soils in a seasonal tropical rainforest of Xishuangbanna, Southwest China. Ecohydrology, 7, 927-935.

Lowman MD (2001). Plants in the forest canopy: Some reflections on current research and future direction. Plant Ecology, 153, 39-50.

Lowman MD (2009). Canopy research in the twenty-first century: A review of arboreal ecology. Tropical Ecology, 50, 125-136.

Lowman MD, Rinker HB (2004). Forest Canopies. 2nd edn. Elsevier Academic Press, London.

Lowman MD, Schowalter TD (2012). Plant science in forest canopies-The first 30 years of advances and challenges (1980-2010). New Phytologist, 194, 12-27.

Lowman MD, Schowalter TD, Franklin JF (2012). Methods in Forest Canopy Research. University of California Press, Oakland, USA.

Lowman M, Devy S, Ganesh T (2013). Treetops at Risk: Challenges of Global Canopy Ecology and Conservation. Springer Science \& Business Media, New York.

Lu HZ, Liu WY, Yu FH, Song L, Xu XL, Wu CS, Lu SG (2015). Higher clonal integration in the facultative epiphytic fern Selliguea griffithiana growing in the forest canopy compared with the forest understorey. Annals of Botany, 116, 113-122.

Lyons B, Nadkarni NM, North MP (2000). Spatial distribution and succession of epiphytes on Tsuga heterophylla (western hemlock) in an old-growth Douglas-fir forest. Canadian Journal of Botany, 78, 957-968.

Ma KP (2014). Rapid development of biodiversity informatics in China. Biodiversity Science, 22, 251-252. (in Chinese with English abstract) [马克平 (2014). 生物多样性信息 学在中国快速发展. 生物多样性, 22, 251-252.]

Ma KP (2015). Biodiversity monitoring in China: From CFor-

www.plant-ecology.com 
Bio to Sino BON. Biodiversity Science, 23, 1-2. (in Chinese with English abstract) [马克平 (2015). 中国生物多 样性监测网络建设: 从CForBio到Sino BON. 生物多样 性, 23, 1-2.]

Ma WZ, Liu WY, Li XJ (2009). Species composition and life forms of epiphytic bryophytes in old-growth and secondary forests in Mt. Ailao, SW China. Cryptogamie Bryologie, 30, 477-500.

Maruyama M, Bartolozzi L, Inui Y, Tanaka HO, Hyodo F, Shimizu-Kaya U, Itioka T (2014). A new genus and species of myrmecophilous brentid beetle (Coleoptera: Brentidae) inhabiting the myrmecophytic epiphytes in the Bornean rainforest canopy. Zootaxa, 3786, 73-78.

McCune B, Amsberry KA, Camacho FJ, Clery S, Cole C, Emerson C, Felder G, French P, Greene D, Harris R, Hutten M, Larson B, Lesko M, Majors S, Markwell T, Parker GG, Pendergrass K, Peterson EB, Peterson ET, Platt J, Proctor J, Rambo T, Rosso A, Shau D, Turner R, Widmer M (1997). Vertical Profile of epiphytes in a Pacific Northwest old-growth Forest. Northwestence, 71, 145-152.

McCune B, Rosentreter R, Ponzetti JM, Shaw DC (2000). Epiphyte habitats in an old conifer forest in Western Washington, U.S.A. The Bryologist, 103, 417-427.

Mendieta-Leiva G, Zotz G (2015). A conceptual framework for the analysis of vascular epiphyte assemblages. Perspectives in Plant Ecology Evolution and Systematics, 17, 510-521.

Mitchell AW (2001). Introduction-Canopy science: Time to shape up. Plant Ecology, 153, 5-11.

Mitchell AW, Secoy K, Jackson T (2002). The Global Canopy Handbook: Techniques of Access and Study Forest Roof. Global Canopy Programme, Oxford, UK.

Nadkarni NM (1993). Canopy network. Nature, 366, 502.

Nadkarni NM, Parker GG, Ford ED, Cushing JB, Stallman C (1996). The international canopy network: A pathway for interdisciplinary exchange of scientific information on forest canopies. Northwest Science, 70, 104-108.

Nadkarni NM, Parker GG, Lowman MD (2011). Forest canopy studies as an emerging field of science. Annals of Forest Science, 68, 217-224.

Negret BS, Perez F, Markesteijn L, Castillo MJ, Armesto JJ (2013). Diverging drought-tolerance strategies explain tree species distribution along a fog-dependent moisture gradient in a temperate rain forest. Oecologia, 173, 625-635.

Nieder J, Engwald S, Klawun M, Barthlott W (2000). Spatial distribution of vascular epiphytes (including hemiepiphytes) in a lowland amazonian rain forest (Surumoni crane plot) of southern Venezuela. Biotropica, 32, 385-396.

Ozanne C, Anhuf D, Boulter S, Keller M, Kitching RL, Körner C, Dias PS (2003). Biodiversity meets the atmosphere: A global view of forest canopies. Science, 301, 183-186.

Parker GG, Smith AP, Hogan KP (1992). Access to the upper forest canopy with a large tower crane. BioScience, 42, 664-670.
Pennisi E (2005). Forest research. Sky-high experiments. Science, 309, 1314-1315.

Petter G, Wagner K, Wanek W, Delgado EJS, Zotz G, Cabral JS, Kreft H (2015). Functional leaf traits of vascular epiphytes: Vertical trends within the forest, intra- and interspecific trait variability, and taxonomic signals. Functional Ecology, 1-12.

Pounds JA, Fogden MPL, Campbell JH (1999). Biological response to climate change on a tropical mountain. Nature, 398, 611-615.

Rajapakse SI, Thammapala P, Tillekeratne D, Yap S (2004). Host specificity of Asplenium. In: Harrison RD ed. Proceedings of the International Field Biology Course 2004. Lambir Hills National Park, Sarawak, Malaysia.

Ruano-Fajardo G, Rovito SM, Ladle RJ (2014). Bromeliad selection by two salamander species in a harsh environment. PLoS ONE, 9(6), e98474. doi: 10.1371/journal.pone. 0098474.

Scheffers BR, Phillips BL, Shoo LP (2014). Asplenium bird's nest ferns in rainforest canopies are climate-contingent refuges for frogs. Global Ecology \& Conservation, 2, 37-46.

Schmit V (2007). Ant-garden epiphytes are protected against drought in a venezuelan lowland rain forest. Ecotropica, 13(2), 93-100.

Schmit-Neuerburg VM (2002). Dynamics of Vascular Epiphyte Vegetation in the Venezuelan Lowland Rain Forest of the Surumoni Crane Project. Rheinische Friedrich-WilhelmsUniversität zu Bonn, Bonn, Germany.

Silvera K, Santiago LS, Cushman JC, Winter K (2009). Crassulacean acid metabolism and epiphytism linked to adaptive radiations in the Orchidaceae. Plant Physiology, 149, 1838-1847.

Song L, Liu WY (2013). Anthropogenic influence on forest canopies-Review of the 6th International Canopy Conference. Acta Ecologica Sinica, 33, 2632-2635. (in Chinese) [宋亮, 刘文耀 (2013). 人类活动对森林林冠的影 响一一第六届国际林冠学大会述评. 生态学报, 33, 2632-2635.]

Song L, Liu WY (2013). Potential impacts of global changes on epiphytic bryophytes in subtropical montane moist evergreen broad-leaved forests, SW China. In: Lowman MD, Devy S, Ganesh T eds. Treetops at Risk: Challenges of Global Canopy Ecology and Conservation. Springer Science \& Business Media, New York.

Song L, Liu WY, Ma WZ, Qi JH (2012a). Response of epiphytic bryophytes to simulated $\mathrm{N}$ deposition in a subtropical montane cloud forest in southwestern China. Oecologia, 170, 847-856.

Song L, Liu WY, Ma WZ, Tan ZH (2011). Bole epiphytic bryophytes on Lithocarpus xylocarpus (Kurz) Markgr. in the Ailao Mountains, SW China. Ecological Research, 26, 351-363.

Song L, Liu WY, Nadkarni NM (2012b). Response of 
non-vascular epiphytes to simulated climate change in a montane moist evergreen broad-leaved forest in southwest China. Biological Conservation, 152, 127-135.

Song L, Ma WZ, Yao YL, Liu WY, Li S, Chen K, Nakamura A (2015a). Bole bryophyte diversity and distribution patterns along three altitudinal gradients in Yunnan, China. Journal of Vegetation Science, 26, 576-587.

Song L, Zhang YJ, Chen X, Li S, Lu HZ, Wu CS, Shi XM (2015b). Water relations and gas exchange of fan bryophytes and their adaptations to microhabitats in an Asian subtropical montane cloud forest. Journal of Plant Research, 128, 573-584.

Still CJ, Foster PN, Schneider SH (1999). Simulating the effects of climate change on tropical montane cloud forests. Nature, 398, 608-610.

Stork NE (2001). The management implications of canopy research. Plant Ecology, 153, 313-317.

Stork NE (2007a). Australian tropical forest canopy crane: New tools for new frontiers. Austral Ecology, 32, 4-9.

Stork NE (2007b). Dynamics and processes in the canopy of an Australian tropical rainforest. Austral Ecology, 32, 2-3.

Stork NE, Wright SJ, Mulkey SS (1997). Craning for a better view: The canopy crane network. Trends in Ecology and Evolution, 12, 418-420.

Szarzynski J, Anhuf D (2001). Micrometeorological conditions and canopy energy exchanges of a neotropical rain forest (Surumoni-Crane Project, Venezuela). Plant Ecology, 153, 231-239.

Testo W, Sundue M (2014). Primary hemiepiphytism in Colysis ampla (Polypodiaceae) provides new insight into the evolution of growth habit in ferns. International Journal of Plant Sciences, 175, 526-536.

Wagner K, Mendieta-Leiva G, Zotz G (2015). Host specificity in vascular epiphytes: A review of methodology, empirical evidence and potential mechanisms. AoB Plants, 7, plu092.

Woods C (2013). Factors Influencing the Distribution and Structure of Tropical Vascular Epiphyte Communities at Multiple Scales. Clemson University, Clemson, USA.

Woods CL, Cardelus CL, DeWalt SJ (2015). Microhabitat associations of vascular epiphytes in a wet tropical forest canopy. Journal of Ecology, 103, 421-430.

Xu HQ, Liu WY (2005). Species diversity and distribution of epiphytes in the montane moist evergreen broad-leaved forest in Ailao Mountain, Yunnan. Biodiversity Science, 13, 137-147. (in Chinese with English abstract) [徐海清, 刘文耀 (2005). 云南哀牢山山地湿性常绿阔叶林附生 植物的多样性和分布. 生物多样性, 13, 137-147.]

Yang J, Chen WH, Shui YM, Sheng JS (2008). Investigating methods of epiphytes in forest canopy. Journal of Wuhan Botanical Research, 26, 661-667. (in Chinese with English abstract) [杨洁, 陈文红, 税玉民, 盛家舒 (2008). 林冠附生植物观测方法概述. 武汉植物研究, 26,
661-667.]

Zhang SB, Dai Y, Hao GY, Li JW, Fu XW, Zhang JL (2015). Differentiation of water-related traits in terrestrial and epiphytic Cymbidium species. Frontiers in Plant Science, 6, 260.

Zhao MX, Geekiyanage N, Xu JC, Khin MM, Nurdiana DR, Paudel E, Harrison RD (2015). Structure of the epiphyte community in a tropical montane forest in SW China. PLoS ONE, 10(4), e0122210. doi: 10.1371/journal.pone. 0122210.

Zhu H (2000). Ecology and Biogeography of the Tropical Dipterocarp Rain Forest in Xishuangbanna. Yunnan Science and Technology Press, Kunming. (in Chinese) [朱华 (2000). 西双版纳龙脑香热带雨林生态学与生物地理学 研究. 云南科技出版社, 昆明.]

Zhu H, Wang H, Zhou SS (2010). Species diversity, floristic composition and physiognomy changes in a rainforest remnant in southern Yunnan, China after 48 years. Journal of Tropical Forest Science, 22, 49-66.

Zotz G (2004). How prevalent is crassulacean acid metabolism among vascular epiphytes? Oecologia, 138, 184-192.

Zotz G (2007a). Johansson revisited: The spatial structure of epiphyte assemblages. Journal of Vegetation Science, 18, 123-130.

Zotz G (2007b). The population structure of the vascular epiphytes in a lowland forest in Panama correlates with species abundance. Journal of Tropical Ecology, 23, 337-342.

Zotz G (2013). 'Hemiepiphyte': A confusing term and its history. Annal of Botany, 111, 1015-1020.

Zotz G, Bader M (2009). Epiphytic plants in a changing world-global: Change effects on vascular and non-vascular epiphytes. In: Lüttge U, Beyschlag W, Büdel B, Francis D eds. Progress in Botany. Springer, Berlin.

Zotz G, Buche M (2000). The epiphytic filmy ferns of a tropical lowland forest-species occurrence and habitat preferences. Ecotropica, 6, 203-206.

Zotz G, Hietz P (2001). The physiological ecology of vascular epiphytes: Current knowledge, open questions. Journal of Experimental Botany, 52, 2067-2078.

Zotz G, Schultz S (2008). The vascular epiphytes of a lowland forest in Panama-Species composition and spatial structure. Plant Ecology, 195, 131-141.

Zotz G, Vollrath B (2003). The epiphyte vegetation of the palm Socratea exorrhiza-Correlations with tree size, tree age and bryophyte cover. Journal of Tropical Ecology, 19, 81-90.

Zotz G, Winkler U (2013). Aerial roots of epiphytic orchids: The velamen radicum and its role in water and nutrient uptake. Oecologia, 171, 733-741.

责任编委: 赵 平 责任编辑: 李 敏

www.plant-ecology.com 


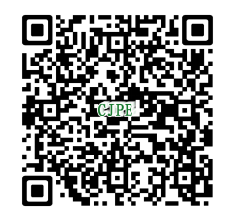

植物生态学报官网

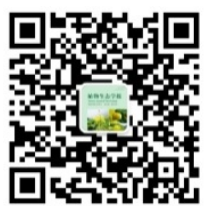

微信订阅号

期刊及学科

相关信息发布

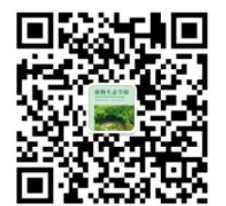

微信服务号

稿件状态查询

全文检索汶览 